\title{
O desafio escolar do ensino por disciplina e a necessidade da religação dos saberes
}

The school chalenge of teaching per subject and the need for knowledge rebinding

Celso José Martinazzo*

Unversidade Regional do Noroeste do Estado do Rio Grande do Sul

Óberson Isac Dresch**

Rede Pública Estadual do Rio Grande do Sul

Resumo Neste texto, propõe-se uma reflexão sobre o desafio da escola em trabalhar a questão do conhecimento sob a forma de disciplina e a necessidade da religação dos saberes. Dentre as múltiplas tarefas que, historicamente, sempre foram atribuições da educação escolar, destaca-se o compromisso com a transmissã̃o e a produção de conhecimentos. Quando se refere à escola como uma agência privilegiada que lida com a questão do conhecimento, depara-se com inúmeras implicações decorrentes dessa afirmação. Procura-se interpretar essas implicações à luz das contribuições dos princípios da teoria da complexidade, por se entender que essa matriz paradigmática se constitui num dos referenciais privilegiados para compreender o processo de produção de um conhecimento pertinente, ou seja, de um conhecimento que, ao mesmo tempo em que distingue, busca promover a religação dos saberes.

PAlAVRAS-ChaVE: Complexidade, Educação escolar, Conhecimento.

\begin{abstract}
In this paper we propose a reflection on the challenge of school to work the question of knowledge in the form of a subject and the need of rebinding the knowledge. Among the many tasks that historically have always been tasks of school education, there is the commitment to transmission and production of knowledge. When referring to the school as a privileged agency dealing with the issue of knowledge, many implications arising from this statement are faced. It is sought to interpret these implications and possibilities in the light of the contributions of the principles of complexity theory due to the understanding that this paradigmatic matrix one of the privileged references for understanding the process of production of relevant knowledge, i.e., a knowledge that, while it distinguish itself, seeks to promote the rebinding of knowledge.
\end{abstract}

KEYWORDS: Complexity, School education, Knowledge. 


\section{Considerações iniciais}

Ao olhar para as instituições escolares nos dias atuais, percebe-se análises e comentários que apontam para um cenário de constantes mudanças, inovações, informatização, descobertas científicas e avanços tecnológicos. Mais que uma mudança de época, tem-se aí configurada uma época de mudanças, acompanhada de indagações e incertezas. Então, como agir em meio a esse processo, uma vez que se é também condicionado e guiado por ele? Que comportamentos adotar a fim de não se tornar meramente reféns da história que está sendo pensada e construída? Mais particularmente, o que a educação escolar, especialmente por meio de seus profissionais, pode esperar e, principalmente, fazer?

Para pensar essa problemática, tem-se como base o paradigma da complexidade, cuja referência principal é para os autores, o pensador francês Edgar Morin. A partir de então o conceito-chave escolhido é o da (re)ligação, que está associado à palavra de origem latina complexus, traduzida como "aquilo que é tecido em conjunto". $O$ verbo complectere, cuja raiz plectere significa trançar, enlaçar, também endossa essa ideia. No caso, a presença do prefixo com representaria o sentido de dualidade entre dois elementos trançados, enlaçados ou entrelaçados intimamente.

Ao projetar caminhos para a educação escolar atual, a noção de "tecido" é algo a ser considerado, pelo fato de propor a religação entre os saberes ou questões presentes nesse contexto. Há saberes que precisam ser (re)ligados, a fim de se cogitar uma compreensão diferente acerca do conhecimento. Assim, promover a religação nos diferentes níveis e situações de aprendizagem é uma instigante diretriz para a função do educador. Sem ignorar a importância do caráter disciplinar do conhecimento, busca-se incentivar um pensar que compreenda e envolva as disciplinas, articulando-as num diálogo entre si e com os respectivos contextos.

\section{Disciplinas: necessárias, porém insuficientes}

As disciplinas assumem um papel importante na formação cognitiva das pessoas. Em seu propósito educativo, elas possibilitam aos estudantes conhecerem diversos saberes já consolidados pela tradição e/ou corroborados pela ciência, os quais constituem a herança que vai sendo transmitida de geração em geração, levando adiante o patrimônio intelectual da humanidade.

Situadas e englobadas no contexto escolar, as disciplinas são partícipes do processo constitutivo do homem e da humanidade, grande finalidade da educação. Savater, ao abordar a questão da condição humana, escreve que "nascemos humanos, mas isso não basta: temos também que chegar a sê-lo" (2005, p. 25-26). Por essa razão, ao pensar a condição da pessoa, pensa-se também a educação e vice-versa. Daí a necessidade de garantir a todos o acesso à escola, à aprendizagem, ao desenvolvimento intelectual, físico, social e cultural proporcionado pelas instituições de ensino. $\mathrm{O}$ conhecimento propicia ao aluno ir crescendo em humanidade. Nesse sentido, destaca Savater que "ser humano consiste na vocação de compartilhar com todos o que já sabemos, ensinando os recém-chegados ao grupo o que devem conhecer para se tornar socialmente válidos" (2005, p. 31). Em síntese, o ato pedagógico contribui, decisivamente, no desenvolvimento humano dos sujeitos, abrangendo suas múltiplas dimensões. 
Young, analisando mais especificamente a herança e riqueza disciplinar, reforça essa reflexão. Segundo ele, as disciplinas

não só oferecem a base para analisar e fazer perguntas sobre o mundo, como também oferecem aos estudantes uma base social para um novo conjunto de identidades como aprendizes. Com as novas identidades referentes às disciplinas, que os estudantes adquirem pelo currículo, acrescentadas àquelas com que vieram para a escola, eles têm mais probabilidades de serem capazes de resistir ao senso de alienação de suas vidas cotidianas fora da escola ou, ao menos, melhor lidar com ele. A escola pode promover tal capacidade. (2011)

Quando se coloca a educação escolar em discussão é necessário ter presente que existe uma herança a ser transmitida, que diz respeito ao passado da humanidade. Sem ele, permanece uma lacuna na preparação da pessoa enquanto ser humano. Também convém pensar o que está por vir, não no sentido de prever ou querer fugir da realidade atual, mas como projeto de vida futura. Entram aí as esperanças, metas e desejos para o futuro. E, ainda, é necessário olhar para o presente, o contexto do qual se faz parte, a cultura, as identidades e diversidades, as conquistas e as dificuldades, enfim, para tudo aquilo que constitui o momento e o espaço em que se está inserido.

Toda essa riqueza preservada não exclui a possibilidade de novas ideias, novos modos de pensar, de acreditar e de ser. E, mais do que isso, ela não elimina a chance de que teorias sejam colocadas sob suspeita, com algumas delas, inclusive, sendo refutadas. Existe, portanto, em meio a todo o conhecimento já consolidado, a presença potencial do erro, do engano, da incerteza, da ilusão. Até mesmo quando parecem esgotadas todas as possibilidades de conhecimento, permanece algo indecifrado e/ou indecifrável. Como observa Morin: "Após toda explicação, todo esclarecimento, toda racionalização, o caráter enigmático persiste. Resolvido o enigma, esta própria solução se torna o grande enigma" (2003, p. 24).

Isso convida a pensar as disciplinas como algo que integra dinamicamente dois importantes movimentos que acompanham as inúmeras investidas pelos saberes: distinguir e associar. Estas são dimensões muito caras para o conhecimento. Se, por um lado, é necessário que se separe e se distinga, por outro, como deixar de lado a síntese e reunião dos elementos? Tem-se, portanto, uma dupla qualidade interligada, e a predominância exacerbada de um desses aspectos sobre o outro pode ter, como consequência, o empobrecimento e a mutilação do conhecimento.

$$
\text { Nas palavras de Marques (2006, p. 41), }
$$

a complexidade que se busca não é a negação da necessária análisedecomposição dos elementos em jogo; é, antes, a consciência operante de que há elementos em jogo, em interação, irredutíveis uns aos outros, diversificados e, como tais, intercomplementares e necessários à compreensão do que se convencionou examinar à parte.

Morin concorda que a distinção e a separação são necessárias para o processo de conhecer: "Precisamos distinguir, separar, esclarecer para conhecer. Nesse sentido, o ato primordial de conhecimento é um ato de separação, uma arrancada da confusão ou da imprecisão; é constituir uma/várias fronteiras" (1986, p. 112). E complementa o autor, entretanto: "é preciso, igualmente, relacionar. Os objetos não 
podem ser considerados como entidades isoladas. Sua própria existência depende de interações com outros 'objetos' e com seu meio" (Idem). Em síntese, conhecer reúne a dupla capacidade de distinguir/separar e, em seguida, relacionar o que foi distinguido/ separado. O verdadeiro problema, todavia, apontado por Morin, "é que nós aprendemos muito bem a separar. É melhor reaprender a religar" (apud PENA-VEGA; ALMEIDA; PETRAGLIA, 2003, p. 52).

Essa chave de leitura ajuda a compreender as disciplinas do conhecimento, mais especificamente aquelas que constituem a estrutura curricular das escolas. É possível trabalhar questões complexas com e nas disciplinas escolares? Pode a disciplina ser complexa, mesmo enquanto disciplina? A fim de continuar refletindo sobre essas perguntas, destaca-se duas características: a disciplina enquanto um saber especializado e insuficiente. Graças à gradual especialização dos saberes, a humanidade fez múltiplas descobertas e obteve muitos avanços. Paralelamente, constata-se que essa especialização, que, em determinados casos atingiu níveis mais minuciosos e profundos, não é suficiente por si só. De outra forma, por mais detalhada e apurada que seja, a especialidade precisa estabelecer vínculos, a fim de não se esclerosar com o tempo.

Morin (2009) concorda que a disciplinaridade tem se mostrado fecunda na história da ciência. Prova disso é sua capacidade de lidar com casos bem delimitados, sendo mais incisiva e precisa em seus estudos ou investigações, encontrando respostas pontuais e provas convincentes. Ou seja, "a disciplinaridade delimita um domínio de competência sem o qual o conhecimento tornar-se-ia fluido e vago" (p. 40). O autor pondera que ela também "desvenda, extrai ou constrói um 'objeto' digno de interesse para o estudo científico" (Idem). Deduz-se, pois, que é preciso considerar o recorte que é feito, esse "objeto construído". Toma-se uma parcela da realidade para poder investigá-la, no entanto outros campos ficam em aberto. Eis, aí, um indício da insuficiência da disciplina.

Em Young (2011), encontramos mais ideias para debater essa questão. Esta realmente se constitui num debate, visto que a leitura predominante, em muitos textos que abordam a problemática da complexidade, faz unicamente a crítica ao caráter disciplinar do conhecimento, enquanto que, aqui, visa-se a encontrar elos entre as disciplinas e o pensamento complexo. Um primeiro ponto apresentado pelo autor é que "as disciplinas são entidades históricas dinâmicas que mudam com o tempo", o que leva a considerar as influências que o contexto histórico e cultural exerce sobre elas. Sendo assim, as disciplinas não ficam presas a um "cânone fixo definido pela tradição, com conteúdos e métodos imutáveis". Ressalta Young, entretanto, que "isso não significa que seja possível haver uma matéria ou uma disciplina sem algum tipo de 'cânone' de textos, conceitos e métodos acordados". Conclui ele que "o cânone em si tem uma história e, embora não seja fixo e imutável, tem uma estabilidade, bem como uma abertura em que os estudantes podem apoiar-se ao estabelecerem suas identidades"(2011).

As disciplinas, mesmo com as suas fronteiras estabelecidas para investigar aspectos do mundo ao longo do tempo, oferecem referenciais básicos para os alunos realizarem suas análises e levantarem perguntas acerca da vida e do mundo. Não é esse um meio de a escola promover a capacidade de um pensar aberto, que traga consigo a herança do passado e que esteja preocupado com problemas da atualidade mas que, inclusive, possam ter efeitos no futuro? Ao trabalhar a disciplina acompanhada de seus contextos, a educação escolar não está contribuindo para a promoção de um entendi- 
mento complexo? E, ainda: "Como é que, em um currículo baseado em disciplinas, os alunos adquirem os recursos para 'fazer conexões' e ganhar um senso do mundo como um 'todo'?' (YOUNG, 2011).

O autor, inicialmente, aponta para a possibilidade de os professores desenvolverem "a capacidade de conectar ou 'atravessar fronteiras"'. Isso não significa que a sua disciplina seja deixada de lado. Pelo contrário, os educadores assumem uma posição privilegiada, ao realizarem estudos no contexto de suas disciplinas, porém é ainda mais importante quando se dão conta de que o conhecimento da vida e do mundo vai muito além dos limites de seu componente curricular. Ao entrar em outros espaços disciplinares, o educador tem presente as respostas e perguntas suscitadas em seu componente. Ele cria uma identidade com o seu objeto de estudo, que tende a ser reforçada na medida em que vai aprofundando a pesquisa, buscando conhecer diferentes possibilidades de entendimento e de explicação. As dúvidas e os problemas que surgem, além de estimularem o aprofundamento disciplinar, fomentam uma incursão "além fronteiras", o que é um ponto de partida para firmar vínculos e ligações com outras disciplinas, em vista de uma aproximação com a complexidade existente.

Origina-se, assim, uma interdisciplinaridade. Não se trata daquela interdisciplinaridade que emerge de maneira forçada, a partir de algum princípio externo imposto, mas que brota do próprio crescimento do conhecimento, ou seja, das suas potencialidades desenvolvidas e da abertura em relação às limitações cognitivas encontradas na disciplinaridade. Dessa forma, a relação entre as disciplinas ocorre com base nas interrogações levantadas na própria disciplina e que ela, por si só, não consegue resolver. Se isso faz sentido, a interdisciplinaridade é muito mais o resultado de situações-problema que se colocam a ser pensadas conjuntamente pelas disciplinas do que propriamente da boa-vontade de se reunir, escolher um tema ou conteúdo e trabalhar coletivamente.

Paviani (1986) entende que a existência das disciplinas, embora seja justificada por razões histórias e didáticas, não garante que elas sejam concebidas ou transformadas em fins em si mesmas. $\mathrm{O}$ autor argumenta. ainda, que o conhecimento não chega a ser um instrumento de solução de problemas que afligem o ser humano e a sociedade apenas por tratar sobre algo de modo a repetir dados, informações, conceitos, princípios e teorias. Ou seja, isso não permite, por si só, "uma efetiva contribuição qualitativa na melhoria cultural e material da vida humana" (p. 80). Também, conforme o autor, "o fundamental, em termos pedagógicos e do progresso científico e filosófico, reside na afirmação popperiana de que 'estudamos problemas, não matérias: problemas que podem ultrapassar as fronteiras de qualquer matéria ou disciplinas” (Idem).

Encontramos, aí, um argumento que reforça a importância dos limites ou fronteiras do conhecimento disciplinar. Estes precisam ser vistos não numa perspectiva negativa, como se fossem barreiras intransponíveis, e sim como elos que possibilitam a continuidade da investigação, do estudo, da descoberta. Diante disso, novas questões surgem e outras voltam à tona: Teriam esses limites e fronteiras alguma relação com as incertezas que acompanham o conhecimento? O complexo, na sua qualidade de religação, de aproximação do que é separado, distinto, não se apresenta potencialmente presente mesmo entre as disciplinas? $\mathrm{O}$ saber disciplinar, criticado por esse movimento pedagógico renovador, que aponta, unicamente, para o poli/inter/pluri/transdisciplinar não é, exatamente, a base de um pensar complexo? 
Cabe, neste momento, uma valiosa ressalva: ao cogitar tais perguntas, a noção que se tem de disciplina não é a de um fim, ou então um sinônimo de conhecimento pleno, enciclopédia do saber. Em outras palavras, o que está em jogo não é chegar ao conhecimento geral, ficando preso aos contornos de um saber isolado. Como promover, no entanto, um conhecimento mais amplo e complexo ignorando a especialidade, a disciplinaridade, a identidade e riqueza particular de um conhecimento? Enfim, escreve Young: "Se você realmente dominar o violino ou o violoncelo, você tem acesso à música que está além de seu instrumento. É isso que penso em relação às disciplinas" (2011).

A fim de continuar esta reflexão, recoloca-se a questão. É possível conhecer além do instrumento, ficando atrelado a ele? Como superar a fronteira disciplinar? Esta, com sua linguagem e conceitos próprios, não estaria isolando uma disciplina das outras, bem como dos problemas e questões que estão para além de seus contornos? Talvez seja esse o paradoxo que acompanha as disciplinas, a ciência e a própria vida, e que exige que essas sejam, ao mesmo tempo, fechadas e abertas. Não seria ele o responsável por evitar que a disciplina se torne algo estanque e estéril? Conclui, ainda, Morin: "Para que nos serviriam todos os conhecimentos parcelares se não os confrontássemos uns com os outros, a fim de formar uma configuração capaz de responder as nossas expectativas, necessidades e interrogações cognitivas?” (2009, p. 51).

Em outro texto, o autor defende que "podemos isolar os elementos que constituem a realidade, porém, cada vez mais, percebemos que eles estão ligados uns aos outros. De alguma forma, as coisas separadas são ligadas e as coisas ligadas são igualmente, de um certo modo, distintas" (MORIN apud PENA-VEGA; ALMEIDA; PETRAGLIA, 2003, p. 51). Tal perspectiva mostra-se razoável no sentido de evitar que a investida pelo conhecimento desande em excessos ou extremos. A dinâmica "isolar-ligar" impede que os saberes sejam esfacelados, fragmentados, enclausurados, o que poderia representar sua exclusão. De outro lado, a dinâmica "ligar-distinguir" evita que tudo seja entendido de forma genérica, ou seja, englobando-se todas as coisas sem a necessária distinção.

O pensamento complexo "deve ultrapassar as entidades fechadas, os objetos isolados, as idéias claras e distintas, mas não deve deixar-se encerrar na confusão, no vago, na ambigüidade, na contradição" (MORIN, 2005, p. 430). Assim, quem sabe, seja possível evitar deslizar para extremos que, de um lado, alimentam modelos unicamente fechados e, de outro, desandam para a aleatoriedade desenfreada, capaz de gerar um estado caótico irreversível.

A mudança proposta por Morin não equivale à supressão das disciplinas, mas na sua religação e no seu revigoramento: "A reforma que visualizo não tem em mente suprimir as disciplinas, ao contrário, tem por objetivo articulá-las, religá-las, dar-1hes vitalidade e fecundidade" $(2009$, p. 35). Uma vez que se aprende muito bem a separar, a isolar, a analisar, a especificar, é necessário, agora, aprender com a mesma maestria a religar. Parece ser esse o caminho da mudança de paradigma. Em síntese, arrisca-se afirmar que o conhecimento pertinente passa por essa constituição de ligações entre os saberes disciplinares, ao passo que as disciplinas isoladas revelam-se cada vez mais insuficientes. 
Aprender a pensar, de forma complexa, requer a inserção prévia das instituições de ensino nesse paradigma. A cabeça bem-feita só é possível quando o próprio ensino se coloca num processo de ampliação e aprofundamento do seu pensar, passando a incorporar e valorizar outras dimensões cognitivas; quando o processo de ensino, de forma ainda mais radical, dispõe-se a reaprender, a se reensinar, enfim, a se reformar e a conhecer o processo de conhecimento. Nesse contexto, ele alarga sua missão, que, de mera transmissão de saberes já formulados, passa a buscar constituir "uma cultura que permita compreender nossa condição e nos ajude a viver, e que favoreça, ao mesmo tempo, um modo de pensar aberto e livre" (MORIN, 2004, p. 11).

Com base nesses argumentos, considera-se que é uma tarefa imprescindível em todo o processo de educação escolar repensar a estrutura paradigmática responsável pela assimilação, apropriação e produção de conhecimentos e que determina, igualmente, a própria compreensão da realidade. A finalidade da ação dos educadores, diferentemente, é fornecer aos educandos "uma cultura que lhes permitirá articular, religar, contextualizar, situar-se num contexto e, se possível, globalizar, reunir os conhecimentos que adquiriram" (MORIN, 2009, p. 31). Isso envolve pensar problemas que encontram alguns indícios e sinais dentro das disciplinas, mas que exijam transgredir a disciplinaridade, buscando alternativas de respostas no diálogo dos saberes. Assim, insiste-se na proposta de uma educação escolar disposta a conceber de modo dialógico os saberes, as disciplinas, o local e o global, enfim, aquilo que se encontra, de um modo ou de outro, envolvido com o conhecimento.

\section{Disciplinas em diálogo no novo Ensino Médio: sinal de um conhecimento pertinente?}

Desde o ano de 2012, no Estado do Rio Grande do Sul, convive-se com novidades e interrogações que acompanham a implantação do Ensino Médio Politécnico. Afinal, o que seria esse "Novo Ensino Médio"? O que proporcionaria aos estudantes, professores, escolas e comunidades? Como poderiam estar sendo desenvolvidos nesse nível de ensino os projetos de pesquisa? Haveria uma estrutura física adequada para atender aos alunos? E os educadores, em geral, já se encontrariam preparados para fazer pesquisa com os educandos?

A pesquisa, que entrou como o "carro-chefe", nesse processo de reestruturação do ensino, representa ainda um desafio para todos, pois instiga a ampliar, aprofundar e/ou modificar a maneira tradicional de ensinar. Até porque, mais que respostas prontas, ela reitera a tese de que perguntas bem feitas são necessárias, pois estimulam os alunos e professores pesquisadores, bem como toda a comunidade escolar, a pensarem e projetarem, coletivamente, possíveis alternativas de qualificação e de educação das pessoas.

Indaga-se se tal modelo tem ajudado a constituir um conhecimento pertinente, capaz de interligar e contextualizar os diferentes saberes. As disciplinas, por sua vez, estão criando uma maior sintonia e articulação entre si? As fronteiras e limitações da disciplinaridade estão sendo envolvidas pela interdisciplinaridade?

Antes de continuar com tais questões, talvez seja conveniente elucidar um pouco o que se entende por conhecimento pertinente. Quando se fala em um saber pertinente, a referência é a uma proposta entendida sob a ótica da complexidade. Sua 
pertinência, portanto, está ligada ao contexto epistemológico orientado pelo conceito do complexo. Ela não corresponde ao fato de envolver muitas informações, conforme afirma Morin: "Um conhecimento não é pertinente porque contém uma grande quantidade de informações. Ao contrário disso, nos damos conta que, freqüentemente, somos submergidos pela quantidade de informações transmitidas pela televisão" (2009, p. 85). Então, o que estaria indicando sua pertinência?

\section{Conforme Morin:}

O conhecimento pertinente é o que é capaz de situar qualquer informação em seu contexto e, se possível, no conjunto em que está inscrita. Podemos dizer até que o conhecimento progride não tanto por sofisticação, formalização e abstração, mas, principalmente, pela capacidade de contextualizar e englobar. (2004, p. 15)

Essas são questões difíceis de serem respondidas. Entende-se, todavia, que um indicativo de resposta passa pela insistência no caráter complexo do conhecimento. Ou seja, se não se conhece qual o melhor rumo a ser tomado, uma opção razoável talvez seja o estabelecimento de relações, ligações, conexões e elos entre disciplinas, grupos, instituições, práticas, visando o máximo de abertura para a teia complexa do conhecimento. Isso sugere entrar no dinamismo dialógico ininterrupto do pensamento, que, segundo Morin (2008), estabelece e atravessa fronteiras, abre e fecha conceitos, vai das partes ao todo e do todo às partes, duvida e crê; recusa e combate a contradição, ao mesmo tempo em que a assume e dela se alimenta.

A pertinência do conhecimento não está na excelência e exclusividade de um único modo de conhecer, mas na capacidade de trabalhar com uma gama de possibilidades. Por isso, a compreensão que resulta da e na complexidade pode ser caracterizada como plural, mas sem perder sua especificidade. Pensar não é seguir um percurso predefinido, baseando-se em um plano tido como padrão. Ao contrário, "pensar é construir uma arquitetura das idéias, e não ter uma idéia fixa. [...] Pensar é reconhecer a validade e situar no mesmo plano a ideia antagônica ou contrária e a idéia poética e genial" (MORIN; CIURANA; MOTTA, 2003, p. 38).

O pensar pertinente está atento à multidimensionalidade dos fenômenos e das disciplinas; disponível até mesmo àquilo que vai além dos limites da racionalidade, ou seja, aos mistérios, às crenças, às sensações. Essa seria, então, a cara da complexidade, o jeito do pensamento complexo, um pensamento que reconhece "a presença do observador/conceituador na observação/concepção, isto é, a presença do sujeito no objeto" (MORIN, 1986, p. 113). Em suma, um pensar que conduz o sujeito a pensar seu próprio pensamento, a pensar-se ao pensar, a conhecer-se ao conhecer.

Um dos avanços da escola pode ser a relativização dos métodos de ensino-aprendizagem tradicionais, em busca de procedimentos mais abertos, flexíveis e contextuais. Refere-se, aqui, a suspender o mero instrucionismo, que equipara conhecimento à assimilação de informações, dando mais espaço para a dimensão autopoiética dos estudantes e dos próprios professores, todos aprendentes. Os "burocratas da educação", afirma Alves, "sempre imaginam que os professores serão 'capacitados' se mais saberes lhes forem acrescentados. Jamais lhes passa pela cabeça que a questão não é somar saberes, mas subtrair saberes [...], para que possam ver as coisas que nunca viram" (2003, p. 32). 
Uma experiência autopoiética que vem sendo intensificada no Rio Grande do Sul desde 2012 é a dos projetos de pesquisa organizados a partir do componente curricular de Seminário Integrado. Tal iniciativa visa a estimular, desde o nível médio de ensino, o desenvolvimento da capacidade investigativa de estudantes e professores. Busca, ainda, um comportamento diferente dos envolvidos nesse processo, que passam a enxergar a pesquisa como um princípio pedagógico. Esta vem somar forças e qualificar ainda mais o papel do ensino dos saberes já consolidados, que constituem o patrimônio do conhecimento.

Em meio a esse contexto, cabe muito bem a ideia desenvolvida por Paviani, quando este autor aponta para a problematização do conhecimento a ser realizada conjuntamente pelos educadores e educandos, a fim de que possam testar seus saberes em relação à realidade da qual fazem parte. Conforme o autor, "[...] aluno e professor precisam saber problematizar o próprio conhecimento adquirido, isto é, pô-lo em constante confronto com a realidade, procurar verificar até que ponto podemos explicar ou interpretar com esses conhecimentos o mundo que nos cerca" (1986, p. 81). A pesquisa, obviamente que em um nível introdutório, tem instigado gradualmente os estudantes a lançar um olhar de curiosidade sobre a realidade do mundo em que vivem, buscando, a partir disso, formular perguntas e buscar respostas para questões que consideram importantes.

Concomitantemente, a prática de pesquisa propicia o desenvolvimento de uma atitude científica, despertando e/ou aperfeiçoando habilidades. Enfim, esse trabalho tem potencializado a capacidade de interpretar, analisar, criticar, refletir, rejeitar ideias fechadas, ensinar/aprender, buscar soluções e propor alternativas para problemas concretos que acompanham sua existência e que necessitam respostas e novas perguntas. Roland Barthes, segundo Alves (2003), teria pronunciado as seguintes palavras iluminadas: "Há uma idade em que se ensina o que se sabe; vem, em seguida outra, em que se ensina o que não se sabe: isso se chama pesquisar. Vem talvez agora a idade de uma outra experiência, a de desaprender" (p. 29).

A educação escolar, por sua vez, pode fazer parte dessa caminhada de revisão e de reflexão. Há saberes a serem sabidos, "des-sabidos" e "re-sabidos". Há perguntas a serem feitas, desfeitas e refeitas. Sendo assim, "a finalidade de nossa escola é ensinar a repensar o pensamento, a 'des-saber' o sabido e a duvidar de sua própria dúvida; esta é a única maneira de começar a acreditar em alguma coisa"(MAIRENA apud MORIN, 2004 , p. 21). Ao seguir por esse caminho, a escola concebe a aprendizagem como a conjugação entre o conhecido e o desconhecido. Nas palavras de Morin, "aprender não é somente reconhecer o que, virtualmente, já era conhecido; não é apenas transformar o desconhecido em conhecimento. É a conjunção do reconhecimento e da descoberta. Aprender comporta a união do conbecido e do desconhecido" (2008, p. 70, grifo do autor).

Organizar e realizar uma educação inspirada nos princípios da complexidade exige muito de todos os educadores. Afinal, é necessário aprender a lidar com saberes que são mais que saberes; a investigar problemas que não dizem apenas a respeito do professor; a conhecer e ministrar disciplinas que vão além das disciplinas isoladas; a pensar questões que são de ordem planetária; a buscar certezas acompanhadas de incertezas, bem como mergulhar nas incertezas sem abrir mão da busca de certezas; enfim, a visar o complexus sem deixar de simplificar quando se fizer necessário. 


\section{Para não concluir}

Entre tantas questões que foram levantadas no texto, é possível encontrar um elo fundamental entre elas: o zelo pelo conhecimento. Em cada ideia apresentada, parágrafo elaborado, pergunta levantada, reflexão feita... existe uma carinhosa preocupação com a instigante temática/problemática do conhecimento, procurando analisar, mais pontualmente, o lugar que este assume na educação escolar.

A educação escolar é desafiada, pois, a se constituir num processo capaz de gerar um ser humano em sintonia com sua época, atento aos diferentes saberes que se colocam lado a lado diariamente. Educar para a vivência, em meio a esse contexto complexo, implica um forte questionamento ao conhecimento fechado, fossilizado, estanque, padronizado, desconectado do todo, que impossibilita um diálogo enriquecedor e construtivo nos ambientes educativos. Todo o cuidado parece pouco quando o que está em jogo é a educação, pois é pela mediação dela que a vida local e planetária pode ir sendo construída num desafio constante à perfectibilidade humana. Em suma,

[...] educar é crer na perfectibilidade humana, na capacidade inata de aprender e no desejo de saber que a anima, é crer que há coisas (símbolos, técnicas, valores, memórias, fatos...) que podem ser aprendidas e que merecem sê-lo, que nós, homens, podemos melhorar uns aos outros por meio do conhecimento. (SAVATER, 2005, p. 22)

Deseja-se que a reflexão, aqui, desenvolvida e os desafios analisados no texto tornem-se importantes referências para que se continue pensando seriamente a educação escolar na perspectiva da complexidade.

\section{Referências}

ALVES, R. A escola com que sempre sonhei sem imaginar que pudesse existir. 5. ed. Campinas: Papirus, 2003.

ASSMANN, H; SUNG, J. M. Competência e sensibilidade solidária: Educar para a esperança. 4. ed. Petrópolis: Vozes, 2000.

CURY, A. O vendedor de sonhos. Rio de Janeiro: Sextante, 2008.

MARQUES, M. O. Pedagogia: a ciência do educador. 3. ed. Ijuí: Ed. Unijuí, 2006.

MORIN, E. A cabeça bem-feita: repensar a reforma, reformar o pensamento. 10. ed. Rio de Janeiro: Bertrand Brasil, 2004.

. Educação e complexidade: os sete saberes e outros ensaios. ALMEIDA, M. da C. de; CARVALHO, E. de A. (Orgs.). 5. ed. São Paulo: Cortez, 2009.

O Método 2: a vida da vida. 3. ed. Porto Alegre: Sulina, 2005.

. M Método 3: o conhecimento do conhecimento. 4. ed. Porto Alegre: Sulina, 2008.

Para sair do século XX. 30. ed. Rio de Janeiro: Nova Fronteira, 1986.

.X da questão: o sujeito à flor da pele. Porto Alegre: Artmed, 2003.

MORIN, E.; CIURANA, E-R.; MOTTA, R. D. Educar na era planetária: o pensamento complexo como método de aprendizagem pelo erro e incerteza humana. São Paulo: Cortez; Brasília: Unesco, 2003. 
PAVIANI, J. Problemas de Filosofia da Educação. 3. ed. Caxias do Sul: Educs, 1986.

PENA-VEGA, A.; ALMEIDA, C. R. S.; PETRAGLIA, I. (Orgs.). Edgar Morin: Ética, Cultura e Educação. 2. ed. São Paulo: Cortez, 2003.

SAVATER, F. O valor de educar. São Paulo: Planeta do Brasil, 2005.

YOUNG, M. F. D. O futuro da educação em uma sociedade do conhecimento: o argumento radical em defesa de um currículo centrado em disciplinas. Revista Brasileira de Educação [online]. 2011, vol.16, n. 48 [citado 2012-10-17], p. 609-623. Disponível em: <http://www. scielo.br/scielo.>. Acesso em: 18 fev. 2013.

* Professor Doutor da Universidade Regional do Noroeste do Estado do Rio Grande do Sul, Santa Rosa, Rio Grande do Sul - Brasil.

** Professor da Rede Pública Estadual do Rio Grande do Sul, Santa Rosa, Rio Grande do Sul - Brasil.

\section{Correpondência}

Celso José Martinazzo - Universidade Regional do Noroeste do Estado do Rio Grande do Sul, Instituto de Filosofia e Ciências Humanas, Curso de Pedagogia. RS 344, Km 39, Timbaúva. CEP: 98900-000 Santa Rosa, Rio Grande do Sul - Brasil.

E-mail:marti.sra@terra.com.br - obersac@yahoo.com.br

Recebido em 24 de junho de 2013

Aprovado em 04 de abril de 2014 
